\title{
WORLD FINANCIAL RELATIONS: UNDERSTANDING THE CREDIT DERIVATIVE SWAPS (CDS) DEPENDENCE STRUCTURE ${ }^{1}$
}

\author{
Fernanda Maria Müller ${ }^{2}$ \\ Marcelo Brutti Righi ${ }^{3}$ \\ Anderson Luis Walker Amorin ${ }^{4}$
}

http://dx.doi.org/10.1590/1413-2311.200.78321

\begin{abstract}
This study investigates the copula model that best fit to model the dependence structure of Credit Derivative Swaps (CDS) spreads. For the analysis, we consider daily data from the period of January 1, 2009 to December 31, 2014. Regarding the models, we considered Vine copulas and Hierarchical Archimedean copulas, and different families of copulas. Our results indicate that C-Vine copulas, as well Student $t$ family, demonstrated better performance, according to the criteria used to get the dependence structure. The best fit of the dependence structure can avoid the model risk, from the use of an incorrect model.
\end{abstract}

Keywords: Credit Derivative Swaps. Model risk. Vine Copulas.

\footnotetext{
${ }^{1}$ Recebido em 27/11/2017, aprovado em 31/05/2018.

${ }^{2}$ Universidade Federal do Rio Grande do Sul (Porto Alegre, RS, Brasil) - fernanda.muller@ufrgs.br

${ }^{3}$ Universidade Federal do Rio Grande do Sul (Porto Alegre, RS, Brasil) - marcelo.righi@ufrgs.br

${ }^{4}$ Universidade Federal do Rio Grande do Sul (Porto Alegre, RS, Brasil) - ander.walker1@ gmail.com
} 


\section{RELACIONES FINANCIERAS INTERNACIONALES: ENTENDIENDO LA ESTRUCTURA DE DEPENDENCIA DE LOS CREDIT DERIVATIVE SWAPS (CDS)}

\section{RESUMEN}

Este estudio investiga el modelo copula que mejor modela la estructura de dependencia de Credit Derivative Swaps (CDS) spreads. Para el análisis se consideraron datos diarios del período comprendido entre el 1 de enero de 2009 y el 21 de diciembre de 2014. Los modelos considerados fueron las Copulas Vine y las Copulas Arquimedianas, con diferentes familias de copulas. Nuestros resultados indican que las copulas C-Vine, así como la familia $t$ Student, demostró mejor desempeño, de acuerdo con los criterios utilizados, para obtener la estructura de dependencia. El mejor ajuste de la estructura de dependencia puede evitar el riesgo del modelo, debido al uso de un modelo inapropiado.

Palabras clave: Credit Derivative Swaps. Riesgo del modelo. Copulas Vine.

\section{RELAÇÕES FINANCEIRAS INTERNACIONAIS: ENTENDENDO A ESTRUTURA DE DEPENDÊNCIA DOS CREDIT DERIVATIVE SWAPS (CDS)}

\section{RESUMO}

Esse estudo investiga o modelo cópula que melhor modela a estrutura de dependência de Credit Derivative Swaps (CDS) spreads. Para a análise foram considerados dados diários do período de 01 de Janeiro de 2009 a 21 de Dezembro de 2014. Os modelos considerados foram as Cópulas Vine e as Cópulas Arquimedianas, com diferentes famílias de cópulas. Nossos resultados indicam que as cópulas C-Vine, bem como a família $t$ Student, demonstrou melhor performance, de acordo com os critérios utilizados, para obter a estrutura de dependência. $\mathrm{O}$ melhor ajuste da estrutura de dependência pode evitar o risco do modelo, decorrente do uso de um modelo inapropriado.

Palavras-Chave: Credit Derivative Swaps. Risco do modelo. Cópulas Vine. 


\section{INTRODUCTION}

Credit derivative swaps (CDS) have become a key innovation in the credit risk market in the last few years, mainly because they are a versatile and adjustable financial instrument that splits the credit exposure of financial products between two or more parties (ALNASSAR et al., 2014). Coudert and Gex (2010) explain that the functionality of a CDS is simple, and that there are three parties involved: the credit buyer (CB), the credit seller (CS), and the reference company (RC). CB therefore buys a CDS from CS against the default risk of RC. CS guarantees to $\mathrm{CB}$ that he will receive a sum that compensates $\mathrm{CB}$ for his loss in the case of an $\mathrm{RC}$ default. To do this, CS receives a percentage of the face value of the debt from $\mathrm{CB}$ for the period of the contract or until RC defaults.

This simplicity and adjustability, along with the efficiency with which the swap acts as a protection tool for financial players, creates a huge market for CDS (ABID; NAIFAR, 2006). In this sense counterpart credit risk is one of the most important drivers of financial markets (ARORA et al., 2012). Because of their importance, these derivative instruments have received attention from regulators, practitioners and researchers.

Correctly modeling the dependence structure of a CDS is important for risk managers in order to set trading limits, for traders in order to hedge the market risk of their credit positions, and for pricing credit derivatives (FEI et al., 2013). Financial assets usually present asymmetry, non-linear dependence, non-normality, and other stylized facts commonly reported in the financial literature. The use of flexible models to deal with these characteristics will help reduce problems arising from the model risk. ${ }^{5}$

Empirical studies on the insurance sector CDS indices have focused on analyzing the dependence of these financial instruments using copulas. Abid and Naifar (2006) applied a copula procedure on CDS from Japanese companies. Chen et al. (2011), who studied the dependence among South American countries during the Argentinian debt crisis in 2001, used a copula approach. Tamakoshi and Hamori (2014) investigated the dependence structure of the CDS indices of the insurance sector in the United States, the European Union, and the United Kingdom. In Gaiduchevici (2015) and Christoffersen et al. (2016) other uses of the copula approach are identified.

Copulas provide a general approach to measuring dependence among groups of random variables; in addition, this approach makes no assumptions about the distribution of returns. In

\footnotetext{
${ }^{5}$ Model risk is related to sources of uncertainty caused by statistical models, such as model choice and the uncertainty of the parameters (parameter risk), according to Alexander and Sarabia (2012).
}

REAd | Porto Alegre - Vol. 23 - No 3 - Setembro / Dezembro 2017 - p. 218-229 
practical applications, the problem is to identify the correct copula to use for modeling the data. For the bivariate case, there are various investigations. However, for multivariate cases, the choice of adequate families is rather limited. An alternative is to use Vine copulas. Vines are a flexible model for describing multivariate copulas using bivariate copulas (KUROWICKA; COOKE, 2006). These constructions decompose a multivariate probability density into bivariate copulas, where each copula can be chosen independently from the others, which results in increased flexibility for modeling the dependence. Another possibility for modeling multivariate dependence through copulas is the Hierarchical Archimedean method.

In this study, we investigate by means of copulas, the dependence structure of the CDS spreads of 20 countries, using daily data from January 1, 2009 to December 31, 2014, which corresponds to 1,565 observations. To reduce model risk resulting from the misspecification of the copula, we carried out an exhaustive investigation to identify which copula models were more appropriate for capturing the international dependence structure of CDS spreads, as well as which model best adjusted the marginal distribution. In this work, we considered Vine copulas and Hierarchical Archimedean copulas, and different families of copulas.

We believe that this study makes two primary contributions to the above strand of the literature. First, it contributes to the identification of the copula model that reduces the model risk of the dependence structure of CDS spreads. Appropriate dependence techniques are of paramount importance in finance, since they are used as input into expensive decisions. On the other hand, our results on the dependence structure are important for regulators wishing to model the regulatory framework of the insurance sector.

\section{COPULAS}

To facilitate the presentation of the copula structure, we focus here on the bivariate case. A function $C:[0,1]^{2} \rightarrow[0,1]$ is a copula for the cases in which $0 \leq \mathrm{x} \leq 1$, and $\mathrm{x}_{1} \leq \mathrm{x}_{2}, y_{1} \leq$ $y_{2},\left(\mathrm{x}_{1}, y_{1}\right),\left(\mathrm{x}_{2}, y_{2}\right) \in[0,1]^{2}$. This function fulfils the following properties:

$$
\begin{aligned}
& C(\mathrm{x}, 1)=C(1, \mathrm{x})=\mathrm{x}, \quad C(\mathrm{x}, 0)=C(0, \mathrm{x})=0, \\
& C\left(\mathrm{x}_{2}, y_{2}\right)-C\left(\mathrm{x}_{2}, y_{1}\right)-C\left(\mathrm{x}_{1}, y_{2}\right)+C\left(\mathrm{x}_{1}, y_{1}\right) \geq 0 .
\end{aligned}
$$

The first property refers to the uniformity of the margins, and the second, the $n$ increasing property, represents the fact that $P\left(\mathrm{x}_{1} \leq \mathrm{X} \leq \mathrm{x}_{2}, \mathrm{y}_{1} \leq \mathrm{Y} \leq \mathrm{y}_{2}\right) \geq 0$ for $(\mathrm{X}, \mathrm{Y})$ with distribution $C$. Sklar (1959) showed that a copula $C$ is connected with a distribution function and its marginal distributions. According to the theorem: 
i) Given a copula $C$, and univariate distribution functions $F_{1}$ and $F_{2}$, a distribution $F$, with marginal distributions $F_{1}$ and $F_{2}$, can be represented by:

$$
F(\mathrm{x}, \mathrm{y})=C\left(F_{1}(\mathrm{x}), F_{2}(y)\right) \text {, for }(\mathrm{x}, \mathrm{y}) \in \mathcal{R}^{2} .
$$

ii) Let $\mathrm{C}$ be a copula that satisfies (3) for a two-dimensional distribution function $F$ with marginal distributions $F_{1}$ and $F_{2} . \mathrm{C}$ is unique if $F_{1}$ and $F_{2}$ are continuous, for every $(\mathrm{x}, \mathrm{y}) \in[0,1]^{2}:$

$$
C(\mathrm{x}, \mathrm{y})=F\left(F_{1}^{-1}(\mathrm{x}), F_{2}^{-1}(\mathrm{y})\right)
$$

where $F_{1}^{-1}(\mathrm{x})$ and $F_{2}^{-1}(\mathrm{y})$ represent the inverse of the marginal distribution functions of $F_{1}$ and $F_{2}$, respectively.

To extend bivariate copulas to the multivariate case, a flexible and intuitive way is to use Vine copulas. In the literature, C-Vines, R-Vines and D-Vines are proposed. For brevity, we present here only the $\mathrm{C}$-Vine copula. In this case, the dependence in relation to a particular variable, the first root node, is modeled using bivariate copulas for each pair. In conformity with the work of Brechmann and Schepsmeier (2013), a root node is generally selected in each tree, and all pairwise dependencies, with respect to this node, are modeled conditioned on all previous root nodes. The structure is similar to a star, as can be seen in Figure 1. The C-Vine density, with root nodes $1, \ldots, d$, is represented by:

$$
f(\mathrm{x})=\prod_{k=1}^{d} f_{k}\left(\mathrm{x}_{k}\right) * \prod_{i=1}^{d-1} \prod_{j=1}^{d-i} c_{i, i+j \mid 1:(i-1)}\left(F\left(\mathrm{x}_{i} \mid \mathrm{x}_{1}, \ldots, \mathrm{x}_{i-1}\right), F\left(\mathrm{x}_{i+j} \mid \mathrm{x}_{1}, \ldots, \mathrm{x}_{i-1}\right) \mid \boldsymbol{\theta}_{i, i+j \mid 1:(i-1)}\right),
$$

where $f_{k}, k=1, \ldots, d$ represent the marginal densities and $c_{i, i+j \mid 1:(i-1)}$ are the bivariate copula densities with parameter(s) $\boldsymbol{\theta}_{i, i+j \mid 1:(i-1)}$.

\section{EMPIRICAL ANALYSIS}

We used daily data for the CDS spreads of Argentina, Belgium, Brazil, China, Costa Rica, Croatia, France, Germany, Indonesia, Ireland, Italy, Jamaica, Korea, the Czech Republic, Russia, South Africa, Spain, Thailand, Turkey, and the United Kingdom. These countries were selected because they are representatives from different continents and present daily data characterized by periods of turbulence and lulls. Our sample period was from January 1, 2009, to December 31, 2014, which corresponds to 1,565 observations. We used log - returns of CDS spreads in our analysis. 
Table 1 - Descriptive statistics of the log-returns of CDS spreads, from January 2009 to December 2014

\begin{tabular}{l|cccccc}
\hline Countries & Mean & Minimum & Maximum & Std. Dev. & Skewness & Kurtosis \\
\hline Argentine & -0.0003 & -0.5528 & 0.5824 & 0.0496 & 0.9714 & 41.0473 \\
Belgium & -0.0005 & -0.2643 & 0.2198 & 0.0479 & -0.0202 & 4.1972 \\
Brazil & -0.0003 & -0.1835 & 0.1737 & 0.0320 & 0.0783 & 3.2397 \\
China & -0.0005 & -0.2231 & 0.2207 & 0.0352 & 0.1991 & 4.4757 \\
Costa Rica & -0.0001 & -0.3204 & 0.2689 & 0.0417 & 0.0728 & 10.4937 \\
Croatia & -0.0003 & -0.2489 & 0.2324 & 0.0283 & 0.1405 & 13.9121 \\
France & -0.0003 & -0.2339 & 0.361 & 0.0503 & 0.2232 & 5.0577 \\
Germany & -0.0010 & -0.3714 & 0.3187 & 0.0513 & -0.1555 & 6.9442 \\
Indonesia & -0.0009 & -0.2209 & 0.2011 & 0.0324 & 0.1895 & 6.2922 \\
Ireland & -0.0010 & -0.3311 & 0.2537 & 0.0385 & -0.2352 & 10.5687 \\
Italy & -0.0002 & -0.4520 & 0.2220 & 0.0478 & -0.4311 & 7.5565 \\
Jamaica & -0.0003 & -0.4075 & 0.2734 & 0.0246 & -2.9119 & 107.1356 \\
Korea & -0.0011 & -0.1919 & 0.1759 & 0.0365 & 0.2174 & 3.5283 \\
Republic Czech & -0.0008 & -0.3185 & 0.3023 & 0.0359 & 0.3508 & 15.4411 \\
Russia & -0.0003 & -0.2786 & 0.3014 & 0.0524 & 0.0073 & 8.5657 \\
South Africa & -0.0005 & -0.3216 & 0.1868 & 0.0348 & -0.3566 & 7.3664 \\
Spain & -0.0002 & -0.4175 & 0.2826 & 0.0479 & -0.2880 & 6.5781 \\
Thailand & -0.0006 & -0.2059 & 0.1942 & 0.0316 & 0.2080 & 6.8107 \\
Turkey & -0.0006 & -0.2476 & 0.2218 & 0.0329 & -0.0021 & 5.3755 \\
UK* & -0.0011 & -0.2243 & 0.2545 & 0.0420 & 0.1325 & 4.5323 \\
\hline$:$ prepar & & & & & & \\
\hline
\end{tabular}

Source: prepared by authors.

* United Kingdom

Table 1 reports the descriptive statistics of the log-returns of the CDS spreads. Jamaica presented the lowest standard deviation (Std. Dev.), while the CDS spreads for Russia showed the highest standard deviation. In general, skewness values indicate which log-returns are skewed. The series also showed excess kurtosis (they have fat tails), which is common behavior for financial data. The kurtosis value for Jamaica (107.1356) stands out among the results.

In the first step, we estimated the conditional means and variances of the log- returns of the CDS spreads. The Ljung-Box test indicated that there were significant autocorrelations in the series. The conditional mean was adjusted by AR(1) (first-order autoregression) specifications with a constant. Subsequently, we analyzed the presence of conditional 
heteroscedasticity in the residuals of the AR models using the Ljung-Box test applied to the squared standardized residuals and the Lagrange multiplier (LM) test applied to the standardized residuals. The values for these tests indicated the presence of significant conditional heteroscedasticity. In order to model the volatility of the CDS spreads we used GARCH (Generalized Autoregressive Conditional Heteroskedasticity) models. Conditional volatility was estimated using the GARCH, the exponential GARCH (EGARCH) and the GJRGARCH (Glosten-Jagannathan-Runkle GARCH) models. The probability distributions considered were as follows: normal distribution, generalized error distribution (GED), Student $t$ distribution and asymmetric Student $t$ distribution. To compare the fitted models, we analyzed the results using the Akaike information criterion (AIC), the Bayesian information criterion (BIC) and the Hannan-Quinn information criterion (HQIC). Finally, to check the adequacy of the fitted models we conducted an analysis of the residuals. ${ }^{6}$

Our results suggested that the EGARCH model using a generalized error distribution presented the best results according to the AIC, BIC and HQIC. In this way, for the marginal we estimated the $\mathrm{AR}(1)$-EGARCH$(1,1)$, with generalized error distribution. These results are omitted for brevity reasons. The structure of the AR(1)-EGARCH(1,1) model is given by:

$$
\begin{aligned}
& r_{i, t}=\phi_{0}+\phi_{1, t} r_{i, t-1}+\varepsilon_{i, t}, \\
& \varepsilon_{i, t}=\sigma_{i, t} z_{i, t}, \quad z_{i, t} \sim \text { i.i.d. } F(0,1), \\
& \ln \left(\sigma_{i, t}^{2}\right)=\omega+\alpha_{1} g\left(\varepsilon_{i, t}\right)+\beta_{1} \ln \left(\sigma_{i, t-1}^{2}\right),
\end{aligned}
$$

where, for asset $i$ in period $t, r_{i, t}$ is the log-return of the CDS spreads, $\sigma_{i, t}^{2}$ is the conditional variance, $\phi_{0}, \phi_{1}, \omega, \alpha_{1}$ and $\beta_{1}$ are parameters, $\varepsilon_{i, t}$ is the innovation in expectation and $z_{i, t}$ is a white noise process with distribution $F . g($.$) can be written as g\left(\varepsilon_{i, t}\right)=\theta \varepsilon_{i, t}+\gamma\left[\left|\varepsilon_{i, t}\right|-\right.$ $\left.E\left(\left|\varepsilon_{i, t}\right|\right)\right]$, where $\theta$ and $\gamma$ are real constants. We estimated the models using quasi-maximum likelihood. The adjusted models exhibited a good adjustment to the data. The LM test and the Ljung-Box test applied to the squared standardized residuals indicated the adequacy of our models. Besides, the coefficients of the AR(1)-EGARCH(1,1) models were significant. After isolating the marginal behavior, it was possible to conduct a joint analysis free of this marginal influence. We used the residuals series $\boldsymbol{Z}=\left\{z_{i, t}\right\}$ and transformed it into pseudo-observations $\boldsymbol{u}=\{u\} \in[0,1]^{p}$ by inversing the GED distribution fitted to each of them, because of the domain and image definition of the copula functions. With these pseudo-observations, we

\footnotetext{
${ }^{6}$ The results are omitted but will be sent upon request.

REAd | Porto Alegre - Vol. 23 - No 3 - Setembro / Dezembro 2017 - p. 218-229
} 
estimated the C-, D- and R-Vines. ${ }^{7}$ The input order for the countries in the models was the decreasing order of the sum of the absolute Kendall's Tau of a country with all the others. From that, we obtained the following identification order: [1] Italy, [2] Turkey, [3] South Africa, [4] Russia, [5] Spain, [6] Belgium, [7] Brazil, [8] Croatia, [9] China, [10] Ireland, [11] France, [12] Korea, [13] Germany, [14] Czech Republic, [15] Indonesia, [16] Thailand, [17] United Kingdom, [18] Jamaica, [19] Argentina, and [20] Costa Rica.

We considered the following copula families: Normal, Student $t$, Gumbel, Frank, Clayton, Joe, BB1, BB7, and BB8. Concerning the estimation of the parameters, we considered an ML estimation procedure that follows a stepwise approach. In the first step, ML estimates separately the parameters in each relationship. The parameter estimations obtained in this first step are known as sequential ML estimates. In the second step, the full log-likelihood function is maximized using the sequential ML estimates as starting values, resulting in the so-called joint ML estimates.

The number of estimated parameters was huge, since there were 19 trees in each structure. To keep this paper brief, we have omitted the estimated parameters, but they are all available upon request. Figures 1 to 3 exhibit plots of the main trees of the C-, D- and R-Vines, respectively. From these plots we have a visual interpretation of how relationships occur. Of course, there would be 18 more plots like this for each structure. We have also omitted these, but they are available upon request. Table 2 shows the fitting results for the models.

\section{Table 2 - Fitting statistics for the C-, D- and R-Vine estimated models}

\begin{tabular}{lrrrr}
\hline Vine type & C-Vine & D-Vine & R-Vine \\
\hline Family & Student $t$ & Student $t$ & Student $t$ \\
AIC & -24804 & -23054 & -24477 \\
BIC & -23267 & -21613 & -23079 \\
LL & 12689 & -1057 & 12499 \\
\hline
\end{tabular}

Source: prepared by authors.

To examine which copula was the best fit for the data, we considered the following criteria: AIC, BIC, and LL (log-likelihood). ${ }^{8}$ We observed that the Student $t$ copula is the

\footnotetext{
${ }^{7}$ We also considered other complex copula constructions, such the Hierarchical Archimedean type, but their performance was much worse than those of the Vines. In higher dimensions, Archimedean copulas have shortcomings for modeling asymmetric and complex dependences structures. For brevity, the results are omitted. ${ }^{8}$ Similar fit tests to choose the best fitting copula were used in Abid and Naifar (2006) and Chen et al. (2008).
}

REAd | Porto Alegre - Vol. 23 - No 3 - Setembro / Dezembro 2017 - p. 218-229 
predominant one, as is quite usual for daily financial returns. Regarding CDS analyses using copulas, Chen et al. (2008), Tamakoshi and Hamori (2014) and Creal and Tsay (2015) also verified that Student $t$ copula are preferred over competing models. Referring to the Vine type, we observed that, according to the values of AIC and BIC, the C-Vine structure had the best fit. For the values of LL, we found that the best value was presented by the D-Vine copula (1057).

A knowledge of the dependence structure among CDS spreads across countries, which shows goodness of fit, is important for investors and regulators, because dependence is an input relevant to portfolio allocation and risk management decisions. The use of families and types of Vine copulas that present a better adjustment allows the regulator or manager to reduce the model risk inherent in the process of estimation of the dependence, and consequently to reduce financial losses arising from the use of an incorrect copula.

\section{Figure 1 - C-Vine tree plot}

\section{Tree 1}

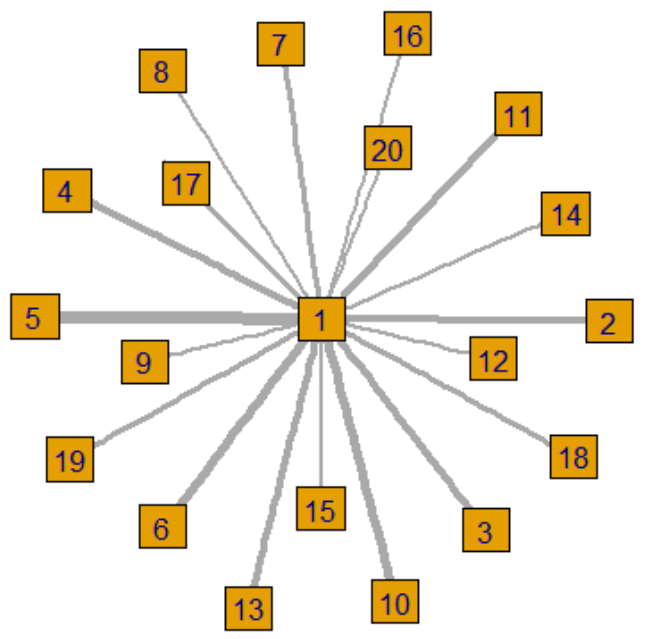

Source: prepared by authors. 


\section{Figure 2 - D-Vine tree plot}

Tree 1

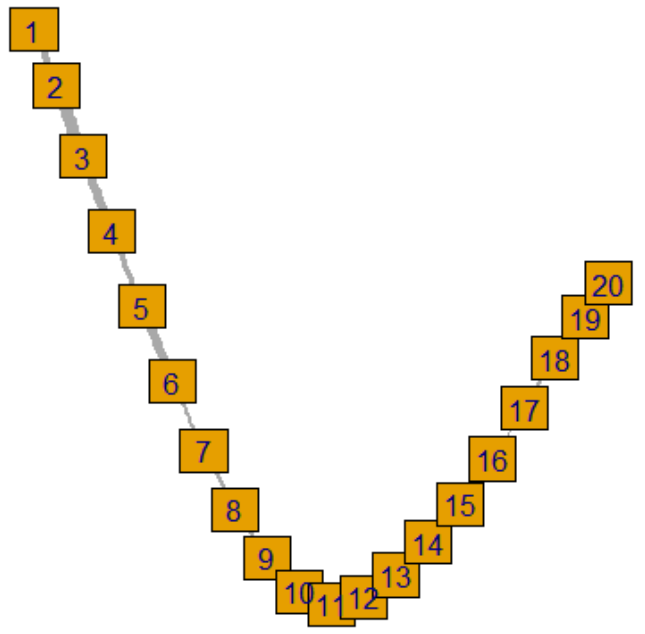

Source: prepared by authors.

\section{Figure 3 - R-vine tree plot}

Tree 1

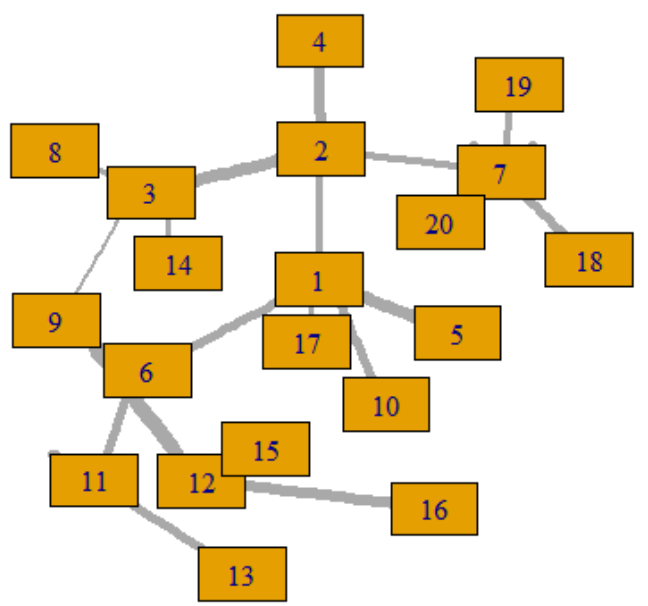

Source: prepared by authors.

REAd | Porto Alegre - Vol. 23 - No 3 - Setembro / Dezembro 2017 - p. 218-229 


\section{CONCLUSIONS}

Understanding the dependence behavior of CDS spreads is important because of the popularity and liquidity of these instruments in the credit markets. This study focused on determining the copula model that presented the best fit to model dependence structure of CDS spreads in the multivariate context. In the analysis, we considered 20 countries and daily data

for the period from January 1, 2009, to December 31, 2014. The copula model allowed us to capture the nonlinear dependence structure that is usually identified in financial data. From the descriptive analyses, we noticed the presence of stylized facts in the log-returns for CDS. Our main results indicated that the C-Vine structure and the Student $t$ copula family presented the better performance. Thus, this specification is the most appropriate for obtaining the dependence structure of the data considered, and possibly reduces the model risk arising from the use of the wrong model.

\section{REFERENCES}

ABID, N.; NAIFAR, F. A. N. Credit-default swap rates and equity volatility: a nonlinear relationship. The Journal of Risk Finance, v. 7, n. 4, p. 348 - 371, 2006.

ALEXANDER, C.; SARABIA, J. M. Quantile uncertainty and value-at-risk model risk. Risk Analysis, v. 32, n. 8, p. 1293-1308, 2012.

ALNASSAR, W. I.; AL-SHAKRCHY, E.; ALMSAFIR, M.K. Credit derivatives: did they exacerbate the 2007 global financial Crisis? AIG: case study. Procedia - Social and

Behavioral Sciences, v. 109, p. 026 - 1034, 2014.

ARORA, N.; GANDHI, P.; LONGSTAFF, F.A. Counterparty credit risk and the credit default swap market. Journal of Financial Economics, v. 103, n. 2, p. 280-293, 2012. BRECHMANN, E.C.; SCHEPSMEIER, U. Modeling dependence with C-and D-vine copulas: the R-package CDVine. Journal of Statistical Software, v. 52, n. 3, 1-27, 2013. CHEN, Y.-H.; WANG, K.; TU, A. H. Default correlation at the sovereign level: evidence from some Latin American markets. Applied Economics, v. 43, n. 11, p. 1399-1411, 2011. CHEN, Y.-H.; TU, A. H.; WANG, K. Dependence structure between the credit default swap return and the kurtosis of the equity return distribution: evidence from Japan. Journal of International Financial Markets, Institutions and Money, v. 18, n. 3, p. 259-271, 2008. CHRISTOFFERSEN, P.; JACOBS, K.; JIN, X.; LANGLOIS, H. Dynamic dependence and diversification in corporate credit. Working Paper, 2016.

REAd | Porto Alegre - Vol. 23 - No 3 - Setembro / Dezembro 2017 - p. 218-229 
COUDERT, V.; GEX, M. The credit default swap market and the settlement of large defaults. International economics, v. 123, p. 91-120, 2010.

CREAL, D.D.; TSAY, R.S. High Dimensional dynamic stochastic copula models. Journal of Econometrics, v. 189, n. 2, p. 335 - 345, 2015.

FEI, F.; FUERTES, A.M.; KALOTYCHOU, E. Modeling dependence in CDS and equity markets: dynamic copula with markov-switching. Working Paper, 2013.

GAIDUCHEVICI, G. Modeling sovereign risk interaction in emerging Europe. Economic Insights, n. 4, v. 2, p. 117-124, 2015.

KUROWICKA, D.; COOKE, R.M. Uncertainty analysis with high dimensional dependence modelling. John Wiley \& Sons, Chichester, 2006.

SKLAR, A. Fonctions de Repartition á n Dimensions et leurs Marges. Publications de l'Institut de Statistique de l'Université de Paris, v. 8, p. 229-231, 1959.

TAMAKOSHI, G.; HAMORI, S. The conditional dependence structures of insurance sector credit default swap indices. North American Journal of Economics and Finance, v. 30, n. 1, 22-132, 2014. 